\title{
BMJ Open Lifestyle-related diseases following the evacuation after the Fukushima Daiichi nuclear power plant accident: a retrospective study of Kawauchi Village with long-term follow-up
}

\author{
Daniel K Ebner, ${ }^{1,2}$ Megumi Ohsawa, ${ }^{1}$ Keiko Igari, ${ }^{3}$ Kouji H Harada, ${ }^{1}$ Akio Koizumi ${ }^{1}$
}

To cite: Ebner DK,

Ohsawa M, Igari $\mathrm{K}$, et al. Lifestyle-related diseases following the evacuation after the Fukushima Daiichi nuclear power plant accident: a retrospective study of Kawauchi Village with longterm follow-up. BMJ Open 2016;6:e011641.

doi:10.1136/bmjopen-2016011641

- Prepublication history and additional material is available. To view please visit the journal (http://dx.doi.org/ 10.1136/bmjopen-2016011641).

DKE and MO joint first author, equal contribution.

Received 23 February 2016 Revised 15 June 2016 Accepted 20 June 2016

\section{CrossMark}

\footnotetext{
${ }^{1}$ Department of Health and Environmental Sciences, Kyoto University Graduate School of Medicine, Kyoto, Japan

Brown University Alpert Medical School, Providence, Rhode Island, USA

${ }^{3}$ Yufune Health Care Center, Kawauchi Village Office, Fukushima, Japan
}

Correspondence to Dr Akio Koizumi; koizumi. akio.5v@kyoto-u.ac.jp

\section{ABSTRACT}

Objectives: Kawauchi Village lies $20 \mathrm{~km}$ west of the Fukushima Daiichi nuclear power plant. On 16 March 2011, evacuation was ordered due to the threat of radiological exposure, and was lifted in April 2012. In this study, we aimed to evaluate the predisaster and postdisaster health status of the Kawauchi Villagers, measured by routine yearly physical examinations.

Methods: We analysed the annual health examination data of residents of Kawauchi Village from 2008 to 2013, as available from the Japanese National Health Insurance system. Data from 2011 were not available due to the disaster. Since the health data included the same participants repeatedly from year to year, the sample was non-independent and generalised estimated equation modelling was used. A predisaster time period (2008-2010) was categorised for comparison with postdisaster 2012 and 2013. The outcome examined was the prevalence of metabolic disease, and was adjusted for confounding factors.

Results: Data for $20.6 \%-25.9 \%$ of the total residents were available in this period. In 2013, the prevalence of metabolic syndrome (from $17.0 \%$ to $25.2 \%, p<0.001$ ), diabetes (from $11.3 \%$ to $17.0 \%, p<0.001$ ), dyslipidaemia (from $43.2 \%$ to $56.7 \%, p<0.0001$ ), hyperuricaemia (from $5.2 \%$ to $8.4 \%, p=0.006$ ) and chronic kidney disease (from $16.1 \%$ to $26.7 \%$, $p<0.001$ ) was found to be elevated significantly compared to predisaster years, while that of obesity or hypertension did not change.

Conclusions: The present follow-up study for Kawauchi Village revealed an increase in lifestylerelated disease following the March 2011 disaster and subsequent evacuation, and this trend still continues 2 years later.

\section{INTRODUCTION}

On 11 March 2011, a historic magnitude 9.0 earthquake struck the northeastern coast of Japan. Located in the mountains, Kawauchi Village, in Fukushima Prefecture, escaped

\section{Strengths and limitations of this study}

- Kawauchi Village consists of the first residents returning to their homes following evacuation from the 2011 Tohoku earthquake/tsunami disaster. This study revealed that the risk of various lifestyle-related diseases increased following the disaster and evacuation and that this trend was continuing 2 years later.

- The data consist of all residents of the village who attended their yearly health consultation, in accordance with the Japanese National Healthcare System. As such, there may be an inherent selection bias.

- Outside of standard blood/metabolic laboratory testing, lifestyle habits were gathered by survey. This may have introduced a self-reporting bias.

major damage from both the earthquake and subsequent tsunami. However, the village lies $20 \mathrm{~km}$ west of the Fukushima Daiichi nuclear power plant, and was bisected by the 16 March government-ordered mandatory evacuation. The entire village population relocated to nearby evacuation centres, such as Koriyama City. The government authorised return to the village a year later in April 2012. By April 2013, 1299 of the original 2816 villagers had returned $(46.1 \%)$, with more than $70 \%$ of returnees being above the age of 50 years. The fallout surrounding the evacuation, including potential radiological exposure, increases in unemployment, loss of living area and disintegration of families and other social support systems, has constituted innumerable challenges to the returning population. ${ }^{1}$

Numerous studies, both within and outside of Japan, have demonstrated the health impact of disasters and their subsequent personal, environmental and societal responses. After the Great Hanshin Earthquake struck 
Kobe City in 1995, mean blood pressure increased significantly for both those patients who were living in the disaster area, as well as those in the surrounding region. In the former, the elevation in blood pressure peaked in the first week and lasted for 4 weeks, but then returned to baseline within 6 weeks of the disaster. ${ }^{2}$ Similar temporary hypertension was reported after Hurricane Katrina, with glycated haemoglobin (HbA1c) levels also increasing throughout the observational period (616 months postdisaster). ${ }^{3}$ A recent study on the Fukushima region demonstrated the short-term impact of the disaster on metabolic measures within evacuated populations, including differences delineated among those evacuating due to radiological threat and those whose evacuation was due to the destruction of their homes by the tsunami. Significantly higher body weight, body mass index, waist circumference and HbAlc, as well as lower high-density lipoprotein cholesterol (HDL-C) levels, were found 5 months following the earthquake. ${ }^{4}$ An evaluation of diabetes prevalence in the region examined 27486 people who were residents of the 12 municipalities surrounding the Fukushima Daiichi power plant, of which Kawauchi Village is a part. Comparing data from before and after the disaster, the evacuated population was found to have a higher incidence of diabetes than those who remained unevacuated. ${ }^{5}$

However, the majority of studies available report only short-term observations, with follow-up typically running less than a year. With the exception of temporary hypertension, little research has examined whether postdisaster metabolic changes return to baseline over time. ${ }^{6}$

The triple threat of earthquake, tsunami and radiological damage from the Tohoku disaster is unprecedented. However, studies have demonstrated that the risk of radiological exposure and consequential increase in cancer rate in the Tohoku region around the nuclear power plant is low. ${ }^{7-10}$ Since the majority of international attention has been focused on radiological threat to the Tohoku population, it is possible if not likely that changes in metabolic health measures may be overlooked in the region.

In this study, the major objective is to evaluate the predisaster and postdisaster health status of Kawauchi villagers who underwent their yearly medical checkup in accordance with the Japanese National Health Insurance system guidelines, over a multiyear follow-up period. This is the first study to evaluate the long-term impact of the disaster, evacuation and return on postevacuation village-returnee health status.

\section{METHODS}

\section{Population data}

This retrospective study was approved by the ethical review board of the Graduate School of Medicine at Kyoto University (approval number E1809). Japanese ethical guidelines provide for waiver of informed consent for research use of existing medical records after anonymisation. A descriptive and analytical epidemiological study was conducted using medical examination data. The yearly national health screening obtains substantial information about individual residents, and is used for health prevention as dictated by the Japanese Ministry of Health, Labor and Welfare. Japanese National Healthcare System medical examination data, taken by physicians in Kawauchi Village and surrounding evacuation centres from 2008 through 2010, and 2012 through 2013, were obtained. Data from 2011 were excluded due to a low participation rate immediately following the disaster and evacuation. Access to Japanese National Healthcare System data for Kawauchi Village was obtained with permission of the Kawauchi Village mayor. Villagers were offered the opportunity to individually withhold their medical data from the study. The National Healthcare Insurance system covers villagers older than 40, including selfemployed citizens and their families, as well as retirees.

Healthcare records included birthdate, age, gender, height, weight, body mass index (BMI), systolic and diastolic blood pressure, waist circumference, blood glucose, HbAlc, HDL-C, low-density lipoprotein cholesterol (LDL-C), triglyceride (TG), aspartate aminotransferase (AST), alanine aminotransferase (ALT), $\gamma$-glutamyl transpeptidase $(\gamma$-GTP) and from 2010 estimated glomerular filtration rate (eGFR) and serum creatinine. Owing to a change in the measurement of HbAlc from the Japan Diabetes Society standard to the National Glycohemoglobin Standardization Program (NGSP) reference value from 2008 to 2012, the HbAlc values were shifted to NGSP-equivalent values for comparison purposes. ${ }^{11}$

\section{Questionnaire}

Lifestyle-related factors were collected by questionnaire and confirmed by interview, and include sleep patterns, dietary changes, smoking and drinking habits and approximate amount consumed, exercise habits, and medications for blood pressure, diabetes, hypercholesterolaemia and other diseases. Information was further confirmed by interview.

\section{Definitions of lifestyle-related disease}

Metabolic syndrome was defined as the presence of any three abnormal findings of five risk factors: ${ }^{12}$ (1) a waist circumference $\geq 90 \mathrm{~cm}$ in males or $\geq 80 \mathrm{~cm}$ in females, (2) a TG $\geq 150 \mathrm{mg} / \mathrm{dL}(1.7 \mathrm{mmol} / \mathrm{L})$, (3) an HDL-C $<40 \mathrm{mg}$ / $\mathrm{dL}(1.0 \mathrm{mmol} / \mathrm{L})$ in males, $<50 \mathrm{mg} / \mathrm{dL}(1.3 \mathrm{mmol} / \mathrm{L})$ in females, (4) a systolic blood pressure $\geq 130$ and/or diastolic blood pressure $\geq 85 \mathrm{~mm} \mathrm{Hg}$ (with antihypertensive pharmaceutical usage in a participant treated as an alternate indicator), (5) a fasting glucose $\geq 100 \mathrm{mg} / \mathrm{dL}$ (with pharmaceutical treatment for elevated glucose as an alternate indicator).

Obesity was defined as a BMI $\geq 25 \mathrm{~kg} / \mathrm{m}^{2}{ }^{213}$

Hypertension was defined as systolic blood pressure $\geq 140 \mathrm{~mm} \mathrm{Hg}$ and/or diastolic blood pressure $\geq 90 \mathrm{~mm} \mathrm{Hg}$, or if patients were undergoing pharmaceutical treatment for hypertension. ${ }^{14}$ 
Diabetes was defined as a fasting plasma glucose level $\geq 126 \mathrm{mg} / \mathrm{dL} \quad(7.0 \mathrm{mmol} / \mathrm{L})$ and/or an HbAlc level $\geq 6.5 \%$ (NGSP), or if the patient was undergoing treatment for elevated glucose. ${ }^{15}$

Dyslipidaemia was defined as an HDL-C $<40$ and/or LDL-C $\geq 140$ and/or TG $\geq 150$, or when treatment for lipidaemia was noted. ${ }^{16}$

Hyperuricaemia was defined as a uric acid measurement $>7.0 \mathrm{mg} / \mathrm{dL} .^{17}$

Chronic kidney disease (CKD) was defined as an $\mathrm{eGFR}<60 \mathrm{~mL} / \mathrm{min} / 1.73 \mathrm{~m}^{2}{ }^{18}$

\section{Statistical methodology}

Continuous variables were evaluated using analysis of variance ANOVA and Tukey's honest significant difference test to identify differences due to ageing. Significance was defined as a $p$ value $<0.05$. Statistica V.12 software (StatSoft, Tulsa, Oklahoma, USA) was used.

As the health data from 2008 to 2013 included the same participants repeatedly, the sample was considered non-independent and generalised estimating equation modelling was used. ${ }^{19}$ The predisaster time period (2008-2010) was categorised for comparison to the postdisaster 2012 and 2013. The presence or absence of lifestyle-related disease was treated as dependent, with medical examination consultation year, age at time of visit and gender independent, with adjustment for both age and gender. An unstructured correlation structure was used to account for correlation among repeated measures on the same participants. The least-squares means and $\mathrm{OR}$, adjusted for age and gender, were used for repeated measure logistic regression analysis. Significance was set to a level of 0.05. SAS V.9.3 (SAS Institute, Cary, North Carolina, USA) was used for analysis.

\section{RESULTS}

\section{Demographics}

Participants with missing information regarding the use of medications were excluded from this study. When waist circumference (WC) and fasting cholesterol (FBC) were excluded, over $80 \%$ of the total population had all needed data available for analysis (online supplementary material table S1 provides the full list of results). There was no significant difference seen in the excluded population predisaster and postdisaster for either WC or FBC. Data for obesity, high-blood pressure, diabetes and lipid abnormalities were available in more than $80 \%$ of the population (online supplementary material tables S2-S5 provide the full list of results). For CKD and hyperuricaemia, information availability prior to the earthquake was poor, as those evaluations were not recommended by Kawauchi Village (online supplementary material tables $\mathrm{S} 6$ and $\mathrm{S} 7$ provide the full list of results). Overall, we could not determine any systemic bias with regard to data coverage of the population predisaster and postdisaster.

From 2008 to 2013 (excluding 2011), medical examinees (percentage of total population) numbered 777 (24.3\%), 797 (25.7\%), $779(25.9 \%), 674(24.1 \%)$ and $576(20.6 \%)$, respectively (table 1). 'Returnee' was defined as a person who returned to the village from evacuation centres in Koriyama City. Patient screening occurred in either Kawauchi Village or Koriyama City. In 2012, $64 \%$ of Kawauchi medical records available were for returnees versus $36 \%$ who remained evacuated; in 2013 , $83 \%$ belonged to returnees. The average age was significantly different only between 2008 and 2012. No significant differences in gender ratio were seen.

\section{Interview questionnaire analysis}

The results of the health examination interview questions are summarised in table 2. No significant differences were seen in self-reported rates of physical activity, alcohol consumption or tobacco consumption. However, a significant decline was noted in reported sleep quality and dietary habits became less regular.

Medication status for cholesterolaemia changed significantly after the disaster, which resulted from increased prevalence of cholesterolaemia. No significant change was observed in prevalence of hypertension, diabetes or CKD (table 2).

Table 1 Number of participants in Kawauchi Village health checkup under the national health insurance system

\begin{tabular}{|c|c|c|c|c|c|c|}
\hline Examination year & 2008 & 2009 & 2010 & 2011 & 2012 & 2013 \\
\hline Population & 3192 & 3100 & 3004 & 2895 & 2801 & 2794 \\
\hline Participants number & 777 & 797 & 779 & Disaster & 674 & 576 \\
\hline Per cent & 24.3 & 25.7 & 25.9 & & 24.1 & 20.6 \\
\hline In Kawauchi & 777 & 797 & 779 & - & 431 & 477 \\
\hline Evacuated (Koriyama City) & - & - & - & - & 184 & 99 \\
\hline Evacuated (Fukushima Prefecture) & - & - & - & - & 26 & - \\
\hline Evacuated (elsewhere) & - & - & - & - & 33 & - \\
\hline Age $($ mean $\pm S D)$ & $68.6 \pm 11.0$ & $68.3 \pm 11.3$ & $68.0 \pm 11.2$ & - & $66.7 \pm 11.7$ & $68.3 \pm 10.9$ \\
\hline ANOVA $p=0.016$ & $A^{*}$ & $\mathrm{AB}^{*}$ & $A B^{*}$ & - & $B^{*}$ & $\mathrm{AB}^{*}$ \\
\hline Gender (male/female) & $42 \% / 58 \%$ & $43 \% / 57 \%$ & $41 \% / 59 \%$ & - & $44 \% / 56 \%$ & $43 \% / 57 \%$ \\
\hline$\chi^{2}$ Test $p=0.704$ & & & & - & & \\
\hline
\end{tabular}




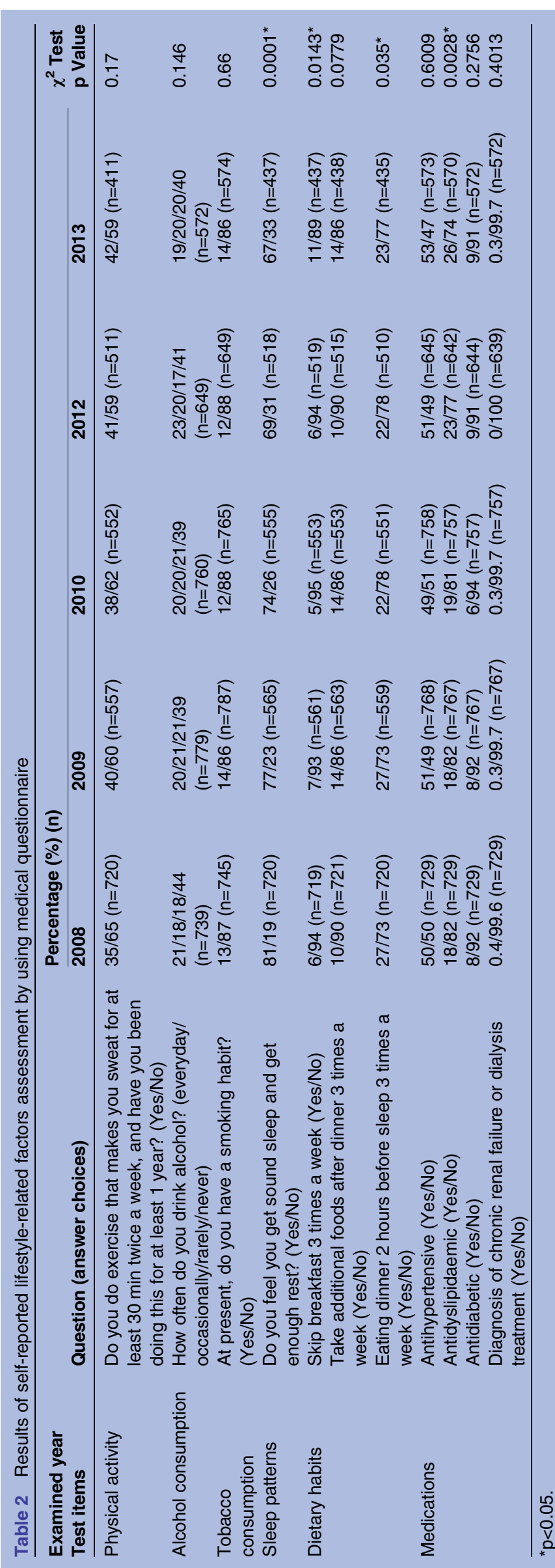

\section{Changes in laboratory value averages}

The trend of the average values of each examined item is listed in table 3. During the study period, a significant change was seen in all values except for AST and creatinine. Abdominal circumference also showed an increasing trend. On comparing medical results from 2012 to any of the pre-earthquake years available, body weight, BMI, fasting blood glucose, TG, ALT and $\gamma$-GTP were significantly increased, while systolic blood pressure and eGFR decreased significantly. On comparing 2013 to all pre-earthquake years, body weight, fasting blood glucose, HbAlc and TG had all increased substantially, while diastolic blood pressure, systolic blood pressure and eGFR were significantly decreased. These differences were tested in relation to patient self-reported physical activity and antihypertensive pharmaceutical usage, but there were no significant correlations noted (table 2).

\section{Lifestyle-related diseases}

Table 4 shows the trends in prevalence of lifestyle-related factors determined by the least squares mean test, adjusted for age and sex, using repeated measure logistic regression analysis with generalised estimating equations. A significant increase was seen in the prevalence of metabolic syndrome, diabetes, dyslipidaemia, hyperuricaemia and CKD in the 2 years following the disaster, even with adjustment for age and gender. Table 5 shows that the OR for 2012, in comparison with preearthquake health values, indicates significantly elevated metabolic syndrome, obesity, diabetes, dyslipidaemia and hyperuricaemia, as well as increased prevalence of CKD. Meanwhile, hypertension decreased significantly. For 2013, the OR indicated significant increases in metabolic syndrome, diabetes, dyslipidaemia and hyperuricaemia, and the prevalence of CKD was elevated, in comparison with the predisaster period. However, significant differences in obesity and hypertension were not seen.

When 2013 was compared to 2012, metabolic syndrome, diabetes and CKD were significantly increased, but obesity had reduced significantly.

\section{DISCUSSION}

On review of the available Kawauchi Village medical records, a significant increase in the prevalence of lifestyle-related diseases was found. Increases were noted in metabolic syndrome, diabetes, dyslipidaemia, hyperuricaemia and CKD following the disaster period. On the other hand, obesity only increased significantly in 2012, and hypertension was significantly reduced. Previous studies of the region had found an increase in diabetes due to evacuation, ${ }^{5}$ and our evaluation of Kawauchi Village, which was fully evacuated, reinforces this result. Further, the increase in diabetes continued over the long term into 2013. This may indicate that it was not the combined stresses of the disaster and evacuation 
Table 3 Demographics of the total Kawauchi population

\begin{tabular}{|c|c|c|c|c|c|c|c|c|c|c|c|}
\hline \multirow{2}{*}{$\begin{array}{l}\text { Examined year } \\
\text { Test items }\end{array}$} & \multicolumn{10}{|c|}{ Mean $\pm S D(n)$ Tukey’s HSD test } & \multirow{2}{*}{$\begin{array}{l}\text { ANOVA } \\
\text { p Value }\end{array}$} \\
\hline & 2008 & & 2009 & & 2010 & & 2012 & & 2013 & & \\
\hline Height & $152.2 \pm 9.8(684)$ & A & $152.7 \pm 9.6(666)$ & A & $153.1 \pm 9.4(650)$ & $A B$ & $154.6 \pm 9.7(572)$ & B & $154.6 \pm 9.6(488)$ & B & $<0.0001^{*}$ \\
\hline Weight & $55.6 \pm 10.4(684)$ & A & $55.8 \pm 10.5(666)$ & A & $55.8 \pm 10.5(650)$ & A & $58.7 \pm 11.1(572)$ & B & $58.1 \pm 11.3(488)$ & B & $<0.0001^{*}$ \\
\hline BMI & $23.9 \pm 3.4(684)$ & $A$ & $23.9 \pm 3.5(666)$ & A & $23.7 \pm 3.5(650)$ & A & $24.5 \pm 3.7(572)$ & B & $24.2 \pm 3.6(488)$ & $A B$ & $<0.0001^{*}$ \\
\hline Waist circumference & $84.3 \pm 9.8(381)$ & $A$ & $84.5 \pm 9.5(382)$ & $A B$ & $85.7 \pm 9.1(391)$ & $\mathrm{ABC}$ & $86.3 \pm 9.7(390)$ & $\mathrm{BC}$ & $87.4 \pm 9.4(296)$ & C & $<0.0001^{*}$ \\
\hline Systolic blood pressure & $135.6 \pm 14.7(684)$ & $A$ & $133.0 \pm 17.5(666)$ & B & $134.6 \pm 17.1(650)$ & $\mathrm{AB}$ & $126.6 \pm 14.3(572)$ & C & $126.2 \pm 14.8(488)$ & C & $<0.0001^{*}$ \\
\hline Diastolic blood pressure & $76.3 \pm 9.2(684)$ & A & $75.2 \pm 9.7$ (666) & $A B$ & $75.9 \pm 10.8(650)$ & $A B$ & $74.5 \pm 9.2(572)$ & B & $71.4 \pm 9.9(488)$ & C & $<0.0001^{*}$ \\
\hline eGFR & - & - & - & - & $72.1 \pm 13.4$ (391) & $A$ & $68.8 \pm 13.9(615)$ & B & $66.0 \pm 12.8(534)$ & C & $<0.0001^{*}$ \\
\hline Blood glucose & $97.4 \pm 16.5$ (596) & $A$ & $96.8 \pm 18.3(544)$ & $A$ & $96.5 \pm 16.0(556)$ & $A$ & $101.0 \pm 21.4(508)$ & $B$ & $103.3 \pm 20.2(425)$ & $B$ & $<0.0001^{*}$ \\
\hline $\mathrm{HbA1c}$ & $5.5 \pm 0.6(676)$ & $A$ & $5.5 \pm 0.7(659)$ & $A$ & $5.5 \pm 0.6(643)$ & $A$ & $5.6 \pm 0.7(572)$ & $A$ & $5.8 \pm 0.8(488)$ & B & $<0.0001^{*}$ \\
\hline HDL-C & $60.1 \pm 14.7(676)$ & A & $59.7 \pm 14.5(659)$ & A & $58.2 \pm 14.1(643)$ & $A B$ & $56.3 \pm 14.4(572)$ & B & $56.7 \pm 13.5(488)$ & B & $<0.0001^{*}$ \\
\hline LDL-C & $114.9 \pm 26.7(676)$ & $A B$ & $113.6 \pm 26.2(659)$ & $A$ & $114.9 \pm 27.0(643)$ & $A B$ & $116.8 \pm 31.3(572)$ & $A B$ & $118.6 \pm 29.8(488)$ & $B$ & $0.033^{\star}$ \\
\hline TG & $97.0 \pm 52.7(676)$ & $A$ & $92.9 \pm 60.0(659)$ & A & $95.8 \pm 55.4(643)$ & $A$ & $109.3 \pm 81.0(572)$ & B & $109.9 \pm 69.7(488)$ & B & $<0.0001^{*}$ \\
\hline AST & $25.8 \pm 8.3(676)$ & - & $27.0 \pm 59.3(659)$ & - & $24.1 \pm 7.6(643)$ & - & $27.3 \pm 11.9$ (572) & - & $25.5 \pm 9.4(488)$ & - & 0.29 * \\
\hline ALT & $19.8 \pm 9.5(676)$ & $A B$ & $19.6 \pm 17.9(659)$ & $A B$ & $18.9 \pm 9.4(643)$ & A & $23.3 \pm 17.2(572)$ & C & $21.5 \pm 13.9(488)$ & $\mathrm{BC}$ & $<0.0001^{*}$ \\
\hline$\gamma$-GTP & $31.0 \pm 34.6(676)$ & $A B$ & $29.9 \pm 34.3(659)$ & $\mathrm{A}$ & $27.9 \pm 27.5(643)$ & $A$ & $37.4 \pm 53.2(572)$ & $\mathrm{C}$ & $36.8 \pm 52.0(488)$ & $\mathrm{BC}$ & $<0.0001^{*}$ \\
\hline Blood creatinine & - & - & - & - & $0.75 \pm 0.23(391)$ & - & $0.77 \pm 0.18(615)$ & - & $0.78 \pm 0.18(534)$ & - & $0.06^{\star}$ \\
\hline Uric acid & $5.08 \pm 1.33(380)$ & $\mathrm{AB}$ & $5.00 \pm 1.29(382)$ & A & $5.00 \pm 1.33(391)$ & A & $5.29 \pm 1.41(615)$ & $\mathrm{B}$ & $5.26 \pm 1.39$ (534) & $B$ & $<0.0001^{*}$ \\
\hline
\end{tabular}

that do not share a letter are significantly different.

$p<0.05:$ Means on the same row that
between $A$ and $B$, or $A B$ and $C$, etc.

ALT, alanine aminotransferase; AST, aspartate aminotransferase; BMI, body mass index; eGFR, estimated glomerular filtration rate; $\gamma$-GTP, $\gamma$-glutamyl transpeptidase; HbA1c, glycated

haemoglobin; HDL-C, high-density lipoprotein cholesterol; HSD, honest significant difference; LDL-C, low-density lipoprotein cholesterol; TG, triglyceride. 
Table 4 Trends in prevalence of lifestyle-related diseases

\begin{tabular}{|c|c|c|c|c|}
\hline \multirow{2}{*}{$\begin{array}{l}\text { Examined year } \\
\text { Test items }\end{array}$} & \multicolumn{3}{|c|}{ Prevalence of lifestyle-related diseases $(95 \% \mathrm{CI})$} & \multirow{2}{*}{$\begin{array}{l}\text { Trend test } \\
\text { p Value }\end{array}$} \\
\hline & pre-earthquake & 2012 & 2013 & \\
\hline Metabolic syndrome & $17.0 \%(15.0$ to 19.2$)$ & $24.2 \%(21.0$ to 27.7$)$ & $25.2 \%(21.9$ to 29.0$)$ & $<0.0001^{*}$ \\
\hline Obesity & $35.3 \%(32.4$ to 38.3$)$ & $39.7 \%$ (36.3 to 43.3$)$ & $36.9 \%(33.4$ to 40.5$)$ & 0.344 \\
\hline Hypertension & $65.7 \%(62.7$ to 68.5$)$ & $61.8 \%(58.2$ to 65.2$)$ & $63.7 \%(59.9$ to 67.4$)$ & 0.246 \\
\hline Diabetes & $11.3 \%(9.6$ to 13.4$)$ & $14.7 \%(12.4$ to 17.3$)$ & $17.0 \%(14.4$ to 20.0$)$ & $<0.0001^{*}$ \\
\hline Dyslipidaemia & $43.2 \%(40.3$ to 46.1$)$ & $53.9 \%(50.2$ to 57.6$)$ & $56.7 \%(52.8$ to 60.6$)$ & $<0.0001^{\star}$ \\
\hline Hyperuricaemia & $5.2 \%(3.9$ to 6.9$)$ & $10.0 \%(7.8$ to 12.7$)$ & $8.4 \%(6.3$ to 11.3$)$ & $0.006^{*}$ \\
\hline Chronic kidney disease & $16.1 \%(12.7$ to 20.1$)$ & $21.7 \%$ (18.5 to 25.3$)$ & $26.7 \%$ (23.0 to 30.8$)$ & $<0.0001^{*}$ \\
\hline
\end{tabular}

Table 5 OR and $95 \%$ Cls of lifestyle-related diseases after the Great East Japan Earthquake

\begin{tabular}{|c|c|c|c|}
\hline \multirow{2}{*}{$\begin{array}{l}\text { Examined year } \\
\text { Test items }\end{array}$} & \multicolumn{3}{|l|}{ OR $(95 \% \mathrm{Cl})$} \\
\hline & 2012 vs pre-earthquake & 2013 vs pre-earthquake & 2013 vs 2012 \\
\hline Metabolic syndrome & $1.55^{\star}(1.29$ to 1.88$)$ & $1.64^{\star}(1.35$ to 2.01$)$ & 1.06 (0.87 to 1.28$)$ \\
\hline Obesity & $1.21^{*}(1.06$ to 1.38$)$ & 1.07 (0.93 to 1.24$)$ & $0.89^{*}(0.79$ to 0.99$)$ \\
\hline Hypertension & $0.85^{\star}(0.75$ to 0.96$)$ & $0.92(0.80$ to 1.06$)$ & 1.09 (0.94 to 1.25$)$ \\
\hline Diabetes & $1.35^{*}(1.13$ to 1.61$)$ & $1.6^{*}(1.32$ to 1.95$)$ & $1.19^{*}(1.02$ to 1.39$)$ \\
\hline Dyslipidaemia & $1.54^{*}(1.33$ to 1.78$)$ & $1.72^{*}(1.47$ to 2.02$)$ & 1.12 (0.95 to 1.32$)$ \\
\hline Hyperuricaemia & $2.03^{*}(1.50$ to 2.75$)$ & $1.69^{*}(1.16$ to 2.45$)$ & 0.83 (0.59 to 1.17$)$ \\
\hline Chronic kidney disease & $1.45^{\star}$ (1.09 to 1.92$)$ & $1.91^{*}(1.43$ to 2.54$)$ & $1.32^{*}(1.10$ to 1.57$)$ \\
\hline
\end{tabular}

alone, but additional stress relating to trouble following the return, including a perceived threat from the nearby Fukushima nuclear power plant.

The nuclear accident impacted Kawauchi Village in a multitude of ways. The changes in population demographics, ongoing evacuation areas and shuttering of businesses resulted in a diminishment of communal resources. Significant portions of the village, including commercial and welfare institutions, healthcare facilities, schools and others, were dependent on the adjacent nuclear power plant in the neighbouring Tomioka Town area, and, as they closed with the changing make-up of the region, there were few if any replacements. Consequently, younger members of the village are not returning, and this has led to a demographic collapse. As of April 2013, only 26\% of former residents below the age of 50 years had returned to the village, and $58 \%$ of those villagers who have returned are 50 years or older. In particular, working-age parents and their children have not returned. This has led to a rapid ageing in the village, as well as causing separation of families and subsequent diminishment in communal support. Furthermore, residents were unable to farm the land in 2012, potentially leading to a diminishment in physical activity among returnees; thankfully, residents were able to resume rice planting in 2013. Taken together, social and mental stress in concert with decreased physical activity may have triggered and continued a universal increase in the prevalence of metabolic illness in the years following the disaster.
Curiously, systolic blood pressure (in 2012 and 2013) and diastolic blood pressure (in 2013) underwent significant decreases, despite no reported change in usage of antihypertension medications, or, as reported by physicians in the village, any noticed change in the kind of antihypertensives generally being provided. Previous reports have shown that blood pressure tends to increase immediately following a disaster, but stabilises in the weeks and months thereafter. ${ }^{2}{ }^{3}$ Since our report looked primarily at long-term outcomes over a year after the disaster period, it would not be possible to detect these short-term changes in blood pressure. Moreover, why systolic and diastolic blood pressure appeared to improve in the population following evacuation remains undetermined, and will require more study.

The rate of diabetes increasing in a postdisaster population, though expected, is a matter for concern. Focused attention on those residents with prediabetic and diabetic symptomologies, and/or on those exhibiting poor sleep and mental stress, may allow health officials to prevent development or worsening of diabetes within the population. ${ }^{20} 21$ However, systemic resources in Kawauchi and the region, and thus the ability to offer population-wide support, remain limited. Notably, the condition in which residents were living did not worsen from 2012 to 2013, and may, in fact, have improved. Unfortunately, however, the rate of lifestyle disease continued to increase. The ability to offer population-wide support may be insufficient at current, and should be empowered. Ongoing health improvement efforts in Kawauchi and the 
surrounding region may thus need to focus on improving the lifestyle of residents on an individual level, in addition to efforts to support rebuilding of the community, regenerate the industry and livelihoods, and bring back younger members of the population.

There were limitations to this study. The data consist of all residents of the village who attended their yearly health examination offered under the Japanese National Healthcare System. Thus, there may be a selection bias in the population. It is conceivable that if the healthiest individuals in the village were the ones to undergo health screening, then the actual health status in the village may be substantially worse than seen here. $^{22}$ Also, even adjusting for age and gender, it is possible that the significant increase seen in lifestyle disease is due to this bias. Conversely, there may be a possibility of overestimation, if those participants more concerned about their health attended the health examination significantly more than did the nonparticipants. We cannot predict in which direction this bias may work.

Further, measurements of patient physical activity, alcohol consumption, tobacco consumption and medication usage, among others, were obtained by self-report or interview, and were not explicitly measured; no differences between these were seen predisaster and postdisaster. There remains a possibility for individual overestimation of physical activity and underestimation of tobacco/alcohol consumption. ${ }^{23}$ Further, since specific questionnaires were used, individualised follow-up was unavailable, and so it is possible that other unidentified causes may be involved in the increase in lifestyle disease. It must be noted that in order to properly diagnose CKD using eGFR, a decrease must be observed over more than 3 months. ${ }^{18}$ However, in our study, only single data points at yearly intervals were available, and so the diagnosis is imperfect. In addition, eGFR was not included in the National Healthcare System data prior to 2010. As such, changes seen over the earthquake time period may have been background changes already occurring prior to the disaster. As a social epidemiological approach was not taken here, future study evaluating specifically the loss of industry and individual livelihood, as well as the subsequent changes in habits and lifestyle, should be performed so as to better grasp the full picture of what changes are occurring in the disaster environment.

\section{CONCLUSIONS}

On examination of Kawauchi Village, it appears that the health status of the villagers has continued to deteriorate in the aftermath of the Tohoku earthquake, tsunami and Fukushima Daiichi nuclear power plant accident. Kawauchi Village and its residents are undergoing difficulties associated with regional degeneration and regeneration following the disaster and subsequent evacuation. It is not enough to focus on individual lifestyle diseases; comprehensive preventative measures must be established to combat lifestyle disease development.

Contributors AK, DKE and MO performed the statistical analysis and drafted the manuscript. $\mathrm{KI}$ and $\mathrm{KHH}$ performed the statistical analysis and helped in drafting and revising the manuscript. AK designed the study. All authors read and approved the final manuscript.

Funding This study was supported by a collaborative research grant from the Disaster Prevention Research Institute, Kyoto University (26P-01). The funder had no role in the study design, data collection, data analysis, data interpretation or writing of the report.

\section{Competing interests None declared.}

Ethics approval This study protocol was approved by the ethical review board of the Graduate School of Medicine at Kyoto University (approval number E1809, 23 July 2013). Japanese ethical guidelines provide for waiver of informed consent for research use of existing medical records after anonymisation. Access to Japanese National Healthcare System data for Kawauchi Village was obtained with permission from the Mayor of Kawauchi Village.

Provenance and peer review Not commissioned; externally peer reviewed.

Data sharing statement No additional data are available.

Open Access This is an Open Access article distributed in accordance with the Creative Commons Attribution Non Commercial (CC BY-NC 4.0) license, which permits others to distribute, remix, adapt, build upon this work noncommercially, and license their derivative works on different terms, provided the original work is properly cited and the use is non-commercial. See: http:// creativecommons.org/licenses/by-nc/4.0/

\section{REFERENCES}

1. Endo Y. Initiatives of Kawauchi village for the return of its residents, and issues. 47th Japan Atomic Industrial Forum Annual Conference, April 2014. Tokyo. http://www.jaif.or.jp/cms_admin/wp-content/ uploads/understanding/annual/47th/47-s3_endo-e.pdf (accessed 1 Aug 2016).

2. Saito K, Kim JI, Maekawa K, et al. The great Hanshin-Awaji earthquake aggravates blood pressure control in treated hypertensive patients. Am J Hypertens 1997;10:217-21.

3. Fonseca VA, Smith $\mathrm{H}$, Kuhadiya $\mathrm{N}$, et al. Impact of a natural disaster on diabetes: exacerbation of disparities and long-term consequences. Diabetes Care 2009;32:1632-8.

4. Tsubokura M, Takita M, Matsumura T, et al. Changes in metabolic profiles after the Great East Japan Earthquake: a retrospective observational study. BMC Public Health 2013;13:267.

5. Satoh H, Ohira T, Hosoya M, et al. Evacuation after the Fukushima Daiichi nuclear power plant accident is a cause of diabetes: results from the Fukushima Health Management Survey. J Diabetes Res 2015;2015:627390.

6. Nomura S, Blangiardo M, Tsubokura M, et al. Postnuclear disaster evacuation and chronic health in adults in Fukushima, Japan: a long-term retrospective analysis. BMJ Open 2016;6:e010080

7. Koizumi A, Harada KH, Niisoe T, et al. Preliminary assessment of ecological exposure of adult residents in Fukushima Prefecture to radioactive cesium through ingestion and inhalation. Environ Health Prev Med 2012;17:292-8.

8. Harada $\mathrm{KH}$, Niisoe $\mathrm{T}$, Imanaka $\mathrm{M}$, et al. Radiation dose rates now and in the future for residents neighboring restricted areas of the Fukushima Daiichi nuclear power plant. Proc Natl Acad Sci USA 2014;111:E914-23.

9. Taira $\mathrm{Y}$, Hayashida N, Orita M, et al. Evaluation of environmental contamination and estimated exposure doses after residents return home in Kawauchi Village, Fukushima Prefecture. Environ Sci Technol 2014:48:4556-63.

10. Yamashita S, Suzuki S. Risk of thyroid cancer after the Fukushima nuclear power plant accident. Respir Investig 2013;51:128-33.

11. Kashiwagi A, Kasuga M, Araki E, et al. International clinical harmonization of glycated hemoglobin in Japan: from Japan Diabetes Society to National Glycohemoglobin Standardization Program values. J Diabetes Investig 2012;3:39-40.

12. Alberti KG, Eckel RH, Grundy SM, et al. Harmonizing the metabolic syndrome: a joint interim statement of the International Diabetes Federation Task Force on Epidemiology and Prevention; National Heart Lung, and Blood Institute; American Heart Association; World Heart Federation; International Atherosclerosis Society; and International Association for the Study of Obesity. Circulation 2009;120:1640-5. 
13. Examination Committee of Criteria for 'Obesity Disease' in Japan; Japan Society for the Study of Obesity. New criteria for 'obesity disease' in Japan. Circ J 2002;66:987-92.

14. Japanese Society of Hypertension. Hypertension Treatment Guidelines 2014. http://www.jpnsh.jp/data/jsh2014/jsh2014v1_1.pdf (accessed 1 Aug 2016).

15. American Diabetes Association. Diagnosis and classification of diabetes mellitus. Diabetes Care 2010;33(Suppl 1):S62-9.

16. Teramoto T, Sasaki J, Ueshima H, et al. Executive summary of Japan Atherosclerosis Society (JAS) guideline for diagnosis and prevention of atherosclerotic cardiovascular diseases for Japanese. $J$ Atheroscler Thromb 2007;14:45-50.

17. Yamanaka $\mathrm{H}$, Metabolism TG. Essence of the revised guideline for the management of hyperuricemia and gout. Japan Med Assoc J 2012;55:324-9.

18. Japan Society of Nephrology CKD Practice Guide. 2012. http://www. jsn.or.jp/guideline/pdf/CKDguide2012.pdf (accessed 1 Aug 2016).

19. McMahon DM, Vdovenko VY, Stepanova YI, et al. Dietary supplementation with radionuclide free food improves children's health following community exposure to (137)Cesium: a prospective study. Environ Health 2015;14:94.

20. Fujihara K, Saito A, Heianza Y, et al. Impact of psychological stress caused by the Great East Japan Earthquake on glycemic control in patients with diabetes. Exp Clin Endocrinol Diabetes 2012;120:560-3.

21. Tanaka M, Imai J, Satoh $\mathrm{M}$, et al. Glycemic control in diabetic patients with impaired endogenous insulin secretory capacity is vulnerable after a natural disaster: study of Great East Japan Earthquake. Diabetes Care 2014;37:e212-13.

22. Ministry of Health Labour and Welfare Grant-in-Aid for Scientific Research Disease, Cardiovascular Disease Disaster Prevention, Diabetes and lifestyle-related diseases countermeasures: study on the development and practice of community health critical for cardiovascular disease prevention with medical examinations and health guidance. 2011. http://mhlw-grants.niph.go.jp/niph/search/ NIDD00.do? resrchNum=201021008B (accessed 1 Aug 2016).

23. Lohne-Seiler $\mathrm{H}$, Hansen $\mathrm{BH}$, Kolle $\mathrm{E}$, et al. Accelerometer-determined physical activity and self-reported health in a population of older adults (65-85years): a cross-sectional study. BMC Public Health 2014;14:284 